\title{
Hoof Pathologies Influence Kinematic Measures of Dairy Cow Gait
}

\author{
F. C. Flower, ${ }^{1}$ D. J. Sanderson, ${ }^{2}$ and D. M. Weary ${ }^{1}$ \\ ${ }^{1}$ Animal Welfare Program, Faculty of Food and Land Systems, and \\ ${ }^{2}$ School of Human Kinetics, The University of British Columbia, Vancouver, V6T 1Z4, Canada
}

\section{ABSTRACT}

To explore how hoof pathologies affect the gait of dairy cattle, we studied gait profiles of cows with no visible injuries $(n=17)$, sole lesions $(n=14)$, and sole ulcers $(n=7)$. Video recordings of dairy cows were digitized using motion analysis software to calculate 6 stride variables for each hoof. Compared with cows with sole ulcers, healthy cows walked faster $(1.11 \pm 0.03$ vs. $0.90 \pm 0.05 \mathrm{~m} / \mathrm{s}$, mean $\pm \mathrm{SEM}$ ), had shorter stride durations (1.26 \pm 0.03 vs. $1.48 \pm 0.05 \mathrm{~s})$, and longer strides $(139.5 \pm 2.1$ vs. $130.0 \pm 3.2 \mathrm{~cm})$. Percentage of triple support in the gait cycle (time when cattle were supported by 3 legs) more than doubled for cows with sole ulcers compared with healthy cows (42 vs. 18\%). Gait differences were likely due to cows reducing the load on an affected leg. Few differences were detected between healthy cows and those with sole lesions, perhaps because of variation in number, severity, and location of injuries. Kinematic gait analysis is a promising approach in understanding how hoof pathologies affect dairy cow gait.

(Key words: dairy cow, lameness, kinematics, hoof pathology)

Abbreviation key: HO = hoof-off, HS = hoof strike, $\mathbf{S L}=$ sole lesions, $\mathbf{S U}=$ sole ulcers.

\section{INTRODUCTION}

In recent years, hoof pathologies have become a focus of research for those concerned with the well-being and productivity of dairy cattle. Studies indicate an increase in the incidence of injuries over the last $25 \mathrm{yr}$, from $5.5 \%$ of dairy cattle in 1977 (Russell et al., 1982) to as much as $55 \%$ in 1991 (Clarkson et al., 1996). Hoof pathologies are of concern not only because of the large number of cows affected, but also because their health is compromised, pain may be experienced, and often cows spend less time feeding resulting in loss of weight

Received January 6, 2005

Accepted June 1, 2005.

Corresponding author: Frances Flower; e-mail: fcf@interchange. ubc.ca. and body condition (O'Callaghan, 2002). In addition, economic costs to producers can be great given the high incidence and cost in lost milk production per cow. Recent studies estimated that over $300 \mathrm{~kg}$ of milk is lost per cow per year because of hoof injuries (Warnick et al., 2001; Green et al., 2002).

Ultimately, effects on both the well-being and productivity of dairy cattle can be reduced by improving early detection and treatment of hoof pathologies. However, early detection is often difficult, because dairy cattle tend to show little overt behavioral response until injuries are advanced (O'Callaghan, 2002) and many cases may persist for months before identification and treatment. To date, there are 2 main approaches to detection of hoof pathologies in research studies. One is to measure the outcome of injuries through behavioral observations of cows with impaired gait (Manson and Leaver, 1988; Sprecher et al., 1997). This approach, however, suffers from a lack of well-defined standards, and relies on the skill of the observer to detect subtle gait abnormalities (Keegan et al., 1998). Significant variation exists both within and between observers probably because of the subjective nature of this approach. For example, O'Callaghan et al. (2003) reported that when an observer scored the gait of the same cows on 3 separate days, only $56 \%$ of scores were identical; and only $37 \%$ agreement was reached between 2 observers scoring the same cows on the same day. A second approach is to score injuries on the hooves (Greenough and Vermunt, 1991). However, injuries such as sole lesions (SL) generally reflect damage incurred months before, and although lesions may be visible, it is not clear whether all are painful.

Biomechanical techniques, including kinematics, can be used to measure cattle gait, and could provide an accurate and objective method of analyzing alterations in hoof movements that may be precursors to clinical lameness. Although kinematic gait analysis has been used extensively in research on horses (Barrey, 1999), this approach has rarely been applied to cow locomotion. Other biomechanical techniques are available to study gait, including force platforms, electromyography, and accelerometers. Kinematics, however, provides a noninvasive technique that also minimizes cow handling. One study calculated basic kinematic mea- 
sures including stride duration, speed, and joint angulations of cows managed in tie-stall, loose-housed, and pasture systems and found that some restrictions in joint movement were evident in those cows kept indoors (Herlin and Drevemo, 1997). More recently, Ceballos et al. (2004) used kinematic techniques to determine spatial requirements of cattle during lying-down with the aim of making recommendations for better stall design. Those authors concluded that kinematic techniques provided an accurate method of assessing cow movement. To our knowledge, however, no previous work using computer-aided kinematic techniques exists to evaluate dairy cattle movement for studying the effects of hoof pathologies.

Two common hoof pathologies found in North America and Europe are SL and sole ulcers (SU; Manske et al., 2002; Somers et al., 2003; Bell, 2004). We hypothesized that these hoof pathologies affect kinematic measures of cow gait. The specific aim of this study was to describe the walking gait profile of cows with no visible injuries and compare this with the profiles of cows having SL and SU.

\section{MATERIALS AND METHODS}

\section{Cows and Management}

This study was conducted on 48 high-producing loosehoused Holstein dairy cows at the University of British Columbia's Dairy Education and Research Centre in Agassiz, Canada. Individual cows were selected randomly with the constraint that 24 primiparous (mean 99 DIM; BCS $=2$ to 3 ) and 24 multiparous cows (parity = 2 to 7 ; mean 73 DIM; BCS $=2$ to 3 ) were used. At the start of the study, primiparous and multiparous cows produced on average $28.5 \pm 4.3$ and $50.4 \pm 7.3 \mathrm{~kg} / \mathrm{d}$ of milk, respectively. Cows were fed twice daily a TMR diet formulated to meet or exceed NRC (2001) requirements for lactating dairy cows. Water was freely available from self-filling troughs. Stalls were deep-bedded with $0.40 \mathrm{~m}$ of sand. Flooring within $1.85 \mathrm{~m}$ of the feed bunk was grooved $2.5 \mathrm{~cm}$-thick rubber. Elsewhere in the pen, flooring was grooved concrete. Cows were milked twice daily in the parlor at 0500 and $1600 \mathrm{~h}$. Cows were cared for according to the standards of the Canadian Council on Animal Care and a protocol approved by the University of British Columbia's Animal Care Committee.

\section{Data Collection}

Video recordings. Every day for $4 \mathrm{wk}$ before initiating data collection, cows were walked along a 40-m grooved concrete test alley to and from the milking parlor. A rope barrier was used to mark a $1.15 \mathrm{~m}$ wide path, forcing cows to walk in a straight line with minimal side-to-side movement and in single file. The cows were allocated to 2 groups for management purposes. The first group of 24 cows was filmed after morning milking (between 0540 and $0810 \mathrm{~h}$ ) for 7 consecutive days and then the procedure was repeated on the second group of 24 cows during the next $7 \mathrm{~d}$. Before each day of recording, the test alley was cleaned with automatic scrapers.

A video camera (Panasonic AG-195MP, Matsushita Electric, Mississauga, ON, Canada), recording at 60 frames per s, was fixed in position $6.75 \mathrm{~m}$ perpendicular to the line of movement of the cows. A 100-W light was attached above the camera and directed at the test alley. The camera was able to capture cows walking the midsection of the test alley (length $7.05 \mathrm{~m}$ ). Cows had one reflective marker, visible from all angles, wrapped around the entire circumference of each leg directly above the metacarpo- and metatarsophalangeal joints. Markers were attached to the cows in the milking parlor $24 \mathrm{~h}$ before the first recording day to allow for habituation and were removed at the end of the 7-d recording period. Markers were made of reflective tape $(0.04 \times 0.22 \mathrm{~m})$ backed with black cloth $(0.15 \times 0.22 \mathrm{~m})$. The back wall of the test alley was also black to provide contrast for digitizing the video. At every recording session, at least 2 consecutive strides were recorded per cow, with the camera recording all 4 hooves from the left lateral side. Cows walked in small groups (2 to 6 individuals) during the recording session and the order and position of cows was noted. At each recording session, spatial calibration of every video clip was performed to allow the data to be converted into metric units. A meter ruler with $0.05 \mathrm{~m}$ of reflective tape attached at each end was held in the middle of the test alley, and calibrated using a custom calibration program in PEAK Motus 3.2 (Peak Performance Technologies, Inc., Englewood, CO). Accuracy of marker position within the calibrated field was determined to be $1 \mathrm{~mm}$ in the sagittal plane.

One observer digitized all cow locomotion using the PEAK system. Video recordings when cows were observed to stop, stumble, slip, defecate, urinate, or perform any gait other than walking were not digitized. Furthermore, recordings were not digitized if reflective markers were missing, or if a cow walking in a group was sufficiently close to the cow in front that her head was lowered and moved from side to side.

Hoof strike (HS) and hoof-off (HO) events were defined visually from the video recordings by the observer. Hoof strike occurred when the hoof was first observed contacting the ground at the beginning of the stance phase. Hoof-off occurred when the hoof was first observed leaving the ground at the end of the stance 
Table 1. Description of stride variables calculated from kinematic measurements.

\begin{tabular}{ll}
\hline Variable & Description \\
\hline $\begin{array}{l}\text { Spatial } \\
\text { Stride length, cm } \\
\text { Maximum stride height, cm }\end{array}$ & $\begin{array}{l}\text { Horizontal displacement between } 2 \text { consecutive hoof strikes of the same hoof } \\
\text { Maximum vertical displacement between } 2 \text { consecutive hoof strikes of the same hoof }\end{array}$ \\
Temporal & Time interval between 2 consecutive hoof strikes of the same hoof \\
Stride duration, s & Time the hoof is in contact with the ground (interval between hoof strike and following hoof-off) \\
Stance duration, s & Time the hoof is not in contact with the ground (interval between hoof-off and following hoof strike) \\
Swing duration, $\mathrm{s}$ & Stride length/stride duration \\
Hoof speed, m/s &
\end{tabular}

phase. Digitized data were smoothed using a fourthorder, zero lag Butterworth filter at a cut-off frequency of $6 \mathrm{~Hz}$ (Winter, 1991). From the coordinate data, 6 stride variables were calculated for each hoof as defined in Table 1.

Clinical assessment of hooves. Previous research has reported that SL and SU take 8 wk to become visible on the sole of the hoof (Bergsten and Herlin, 1996). As the aim of this study was to look at the effects of SL and SU on gait, a professional hoof trimmer trimmed the front and hind hooves of each cow 8 to 9 wk after the trial. An experienced observer examined each hoof and recorded the presence of SL using a modified version of Greenough and Vermunt's (1991) lesion scoring system. Number, location, and severity of SL on each hoof were scored on a 4-point scale [1 = slight discoloration; 2 = moderate hemorrhagic lesion; $3=$ severe hemorrhagic lesion; $4=$ sole ulcer (exposed corium)]. We also noted at this time the presence and location of other foot pathologies such as digital dermatitis, interdigital hyperplasia, and interdigital necrobacillosis.

Hoof health data of 2 cows were not collected because these animals left the trial early; one had coliform mastitis and the other was dried off early for management reasons. Of the 46 cows examined, $63 \%$ had hoof pathologies at the time of hoof examination. The presence of digital dermatitis was noted on 8 cows, but we could not be certain whether this was present at the time of video recording so these animals were dropped from the analysis. The remaining 38 cows were grouped into 3 mutually exclusive hoof health categories: healthy cows with no visible signs of injury or disease on hooves ( $\mathrm{n}=17)$; cows having only SL $(\mathrm{n}=14)$; and SU cows having exposed corium and SL $(n=7)$. No cases of interdigital hyperplasia or interdigital necrobacillosis were recorded.

Morphometric measures. Individual cow body mass was recorded twice during the trial, with $1 \mathrm{wk}$ between recordings. Mean body mass $( \pm$ SD) of healthy (582 kg \pm 72$), \mathrm{SL}(620 \mathrm{~kg} \pm 58)$, and $\mathrm{SU}(676 \mathrm{~kg} \pm 68)$ animals differed $(P<0.05)$ among groups, a difference that was largely due to a 778-kg cow in the SU group. All statistical analyses reported below were conducted with and without this cow. In no case did the inclusion of this data affect the significance of the results reported, so the results described below include this cow.

Nine months after the video recordings, 3 additional morphometric measures were recorded from the 26 cows still available in the herd. Measurements were height at the withers (T3), height at the tailbone (Cc1) and the length of the back (Cc1-T3). All measures were recorded 3 times for each cow from the left lateral side. Measurements were only recorded when cows were standing with their head elevated and legs straight. No differences were detected among groups for any of these 3 measures (Table 2).

\section{Statistical Analyses}

Using the first stride per day, we calculated mean stride variables by averaging across the 4 hooves and $7 \mathrm{~d}$ of video recordings for each cow. Differences between the 3 hoof health groups for the stride variables described in Table 1 (stride length, stride height, stride duration, stance duration, swing duration, and hoof speed) were tested using a one-way ANOVA (SAS Inst., Inc., Cary, NC). To address the specific aims outlined in the introduction, we employed contrast statements to test for differences between healthy cows and cows with SL (1 df), and SU (1 df).

\section{RESULTS}

\section{Stride Variables}

Compared with the healthy group, cows with SU had shorter strides, and during the swing phase, hooves

Table 2. Mean ( \pm SD) morphometric measures of cow height and length.

\begin{tabular}{llll}
\hline Measure & $\begin{array}{l}\text { Healthy } \\
(\mathrm{n}=9)\end{array}$ & $\begin{array}{l}\text { Sole lesions } \\
(\mathrm{n}=13)\end{array}$ & $\begin{array}{l}\text { Sole ulcers } \\
(\mathrm{n}=4)\end{array}$ \\
\hline $\begin{array}{l}\text { Height at withers, cm } \\
\text { Height at tailbone, cm }\end{array}$ & $141 \pm 5$ & $139 \pm 3$ & $144 \pm 1$ \\
Length of back, cm & $143 \pm 4$ & $144 \pm 4$ & $144 \pm 2$ \\
\hline
\end{tabular}


Table 3. Least square means ( \pm SEM) of spatial and temporal stride variables for healthy cows $(\mathrm{n}=17)$ and those with sole lesions (SL; $\mathrm{n}=14$ ), and sole ulcers ( $\mathrm{SU} ; \mathrm{n}=7$ ).

\begin{tabular}{llr}
\hline Variable & $\begin{array}{l}\text { Hoof } \\
\text { condition }\end{array}$ & Mean \pm SEM \\
\hline Spatial & & \\
Stride length, cm & Healthy & $139.5 \pm 2.1$ \\
& SL & $139.3 \pm 2.3$ \\
Maximum stride height, cm & SU & $130.0 \pm 3.2^{*}$ \\
& Healthy & $9.6 \pm 0.2$ \\
& SL & $9.7 \pm 0.2$ \\
& SU & $8.7 \pm 0.3^{*}$ \\
Temporal & & \\
Stride duration, s & Healthy & $1.26 \pm 0.03$ \\
& SL & $1.30 \pm 0.04$ \\
Stance duration, s & SU & $1.48 \pm 0.05^{* * *}$ \\
& Healthy & $0.69 \pm 0.03$ \\
Swing duration, s & SL & $0.75 \pm 0.03$ \\
& SU & $0.91 \pm 0.04^{* * *}$ \\
& Healthy & $0.57 \pm 0.01$ \\
Hoof speed, m/s & SL & $0.55 \pm 0.01$ \\
& SU & $0.57 \pm 0.02$ \\
& Healthy & $1.11 \pm 0.03$ \\
& SL & $1.08 \pm 0.03$ \\
& SU & $0.90 \pm 0.05^{* * *}$ \\
\hline
\end{tabular}

*Different $(P<0.05)$ from healthy cows; **Different $(P<0.01)$ from healthy cows; ${ }^{* * *}$ Different $(P<0.001)$ from healthy cows.

were not raised as high (Table 3). Total stride duration of cows with SU was longer than that of healthy cows. Furthermore, cows having SU spent on average $0.22 \mathrm{~s}$ longer with hooves in ground contact (stance duration) and had a slower average hoof speed than healthy cows ( 0.90 vs. $1.11 \mathrm{~m} / \mathrm{s}$, respectively). No differences were detected between the healthy and SL groups for any spatial or temporal stride variables. As older cows are more susceptible to injuries, we reanalyzed the data considering only multiparous cows. As with the analysis considering all cows, multiparous cows with $\mathrm{SU}(\mathrm{n}=6)$ differed from healthy cows $(n=5)$ in stride length, height, and duration, stance duration and speed $(P<$ 0.05).

Stance and swing durations of cows should not only be considered in absolute values, but also as a proportion of the total stride duration. For example, healthy and SU cows had the same absolute swing durations ( $0.57 \mathrm{~s})$, but as a percentage of stride duration, there was a difference in swing (45 and 39\% respectively) between the 2 groups. The stride cycle (Figure 1) for healthy and SU cows illustrates the stance and swing durations as a proportion of the stride. The HS and HO sequence for each hoof and the number of hooves in ground contact (i.e., double or triple support) is also shown. During the periods of double support, cows alternated between ipsilateral (same side) and diagonal support. Given that the stride variables of SU cows were significantly different from healthy cows, we tested for differences between the proportion of triple support in the strides of healthy cows and those having SU. Healthy cows (Figure 1a) spent only $18 \%$ of the stride in triple support, but this more than doubled ( $42 \%$ of the stride; $P<0.001$ ) for cows with SU (Figure 1b).

\section{Hoof Movement}

For descriptive purposes, hoof trajectories of front and rear hooves (i.e., changes in horizontal and vertical displacement over time) are illustrated in Figure 2. This descriptive analysis corresponds well with the averages and treatment differences described in Table 3. Animals with SU have shorter strides, and hooves are not raised as high, although this difference appears more pronounced for the rear hooves. In addition, it is interesting to note that for all hoof health groups, the front hoof height peaked twice during the swing phase (HO-HS); once shortly after $\mathrm{HO}$, and once before HS.

Individual differences in the type, number, and location of hoof pathologies can complicate comparisons of hoof trajectories. For example, cow 13 had an SU on the right rear hoof combined with minor SL on the left front and left rear hooves, 3 moderate SL on the rear hooves, and 1 severe SL on the right front hoof. The hoof trajectories of this cow were markedly different from healthy cows (Figure 3). The ulcerated right rear hoof not only showed a shorter stride length and a lower maximum stride height, but the stride also reached maximum height earlier than that of healthy cows.

\section{DISCUSSION}

This is the first study to measure successfully the gait of healthy cows and those with hoof pathologies using computer-aided kinematic techniques. Some basic stride measures from this study show good agreement with previous kinematic literature on cow gait. For example, Herlin and Drevemo (1997) reported a mean stride duration for dairy cows of $1.22 \mathrm{~s}$ compared with $1.26 \mathrm{~s}$ for the healthy cows in the current study. However, some stride variables were different to those previously reported. Healthy cows in our study had longer stride lengths (1.40 vs. $1.34 \mathrm{~m}$ ) and faster walking speeds (1.11 vs. $0.80 \mathrm{~m} / \mathrm{s})$ than those reported by Phillips and Morris (2000). However, Phillips and Morris (2000) did not report on hoof health of their cows. Another interesting finding of this study was the difference in hoof trajectory patterns between front and rear hooves of both healthy cows and those with hoof injuries. This difference in hoof trajectory is probably due to the difference in the structural anatomy of the front and rear legs, but further work is required to determine how this relates to the trajectories observed.

Kinematic measures were effective at identifying cows having SU; stride length, height, duration, and 

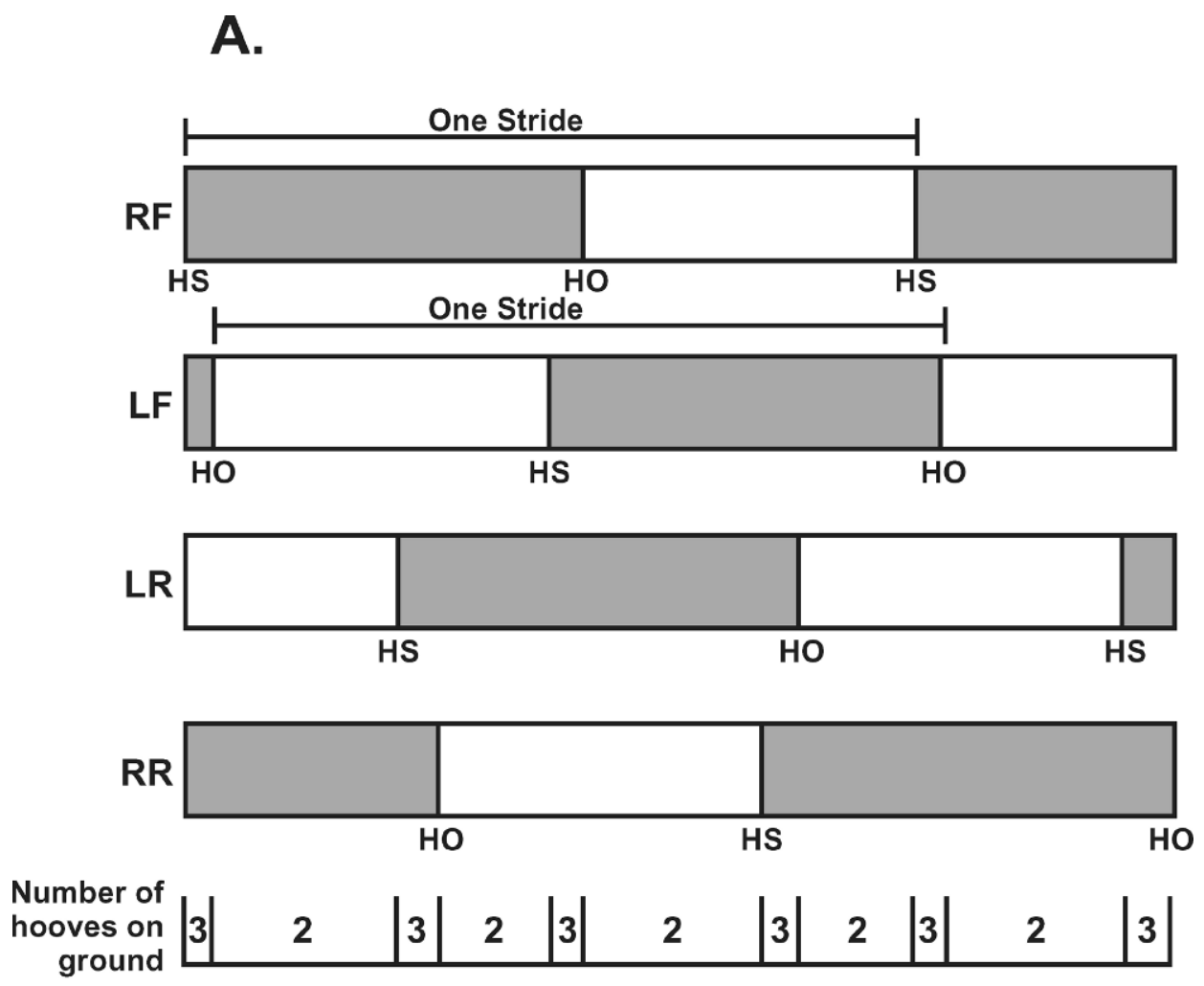

B.
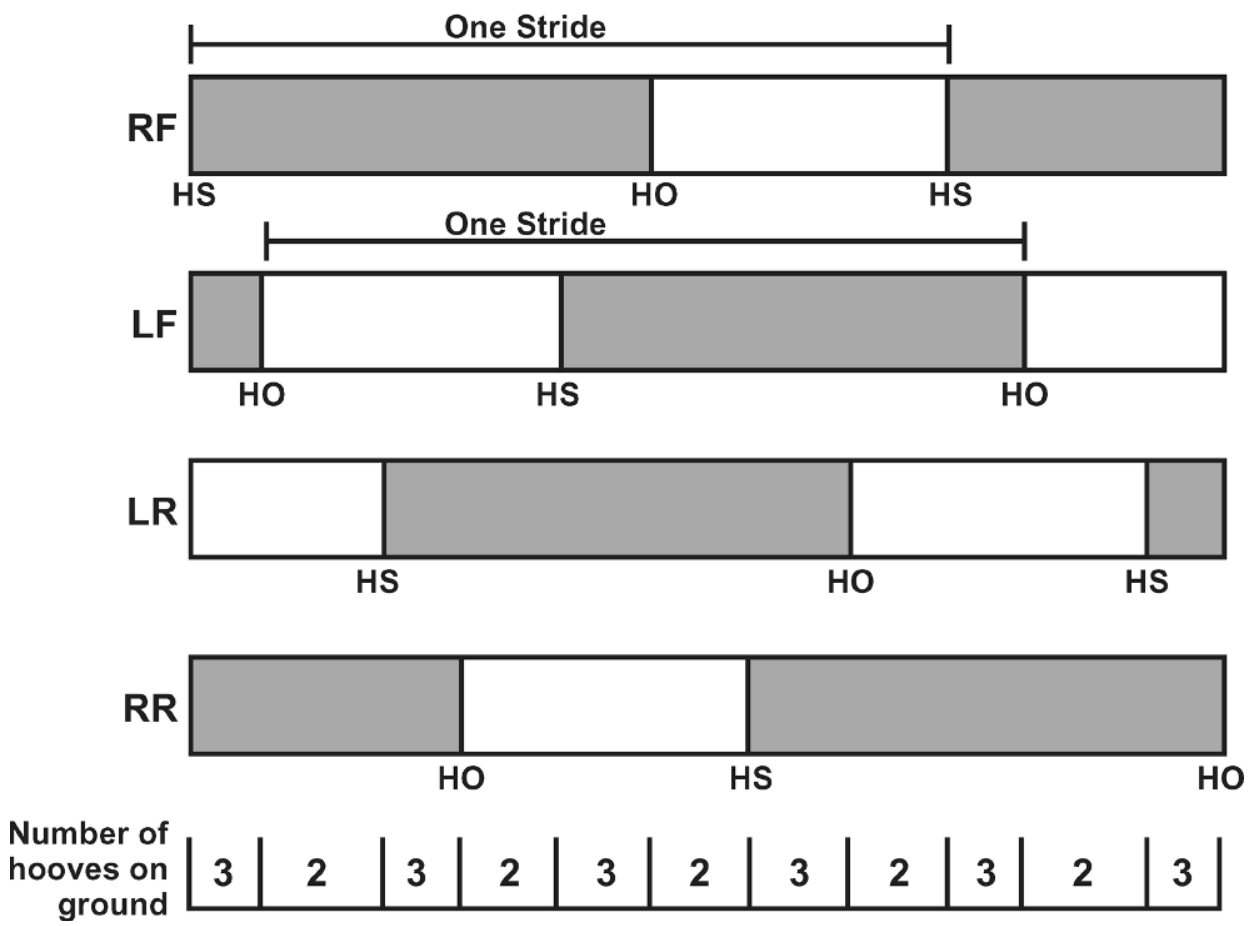

Figure 1. The mean proportion of double and triple support during a single stride [either from hoof strike (HS) to HS or from hoof-off $(\mathrm{HO})$ to $\mathrm{HO}$ ] for each leg for A) healthy cows $(\mathrm{n}=17)$ and $\mathrm{B})$ cows $(\mathrm{n}=7)$ with sole ulcers; $\mathrm{RF}=$ right front hoof, $\mathrm{LF}=$ left front hoof, $\mathrm{LR}=$ left rear hoof, $\mathrm{RR}=$ right rear hoof. 


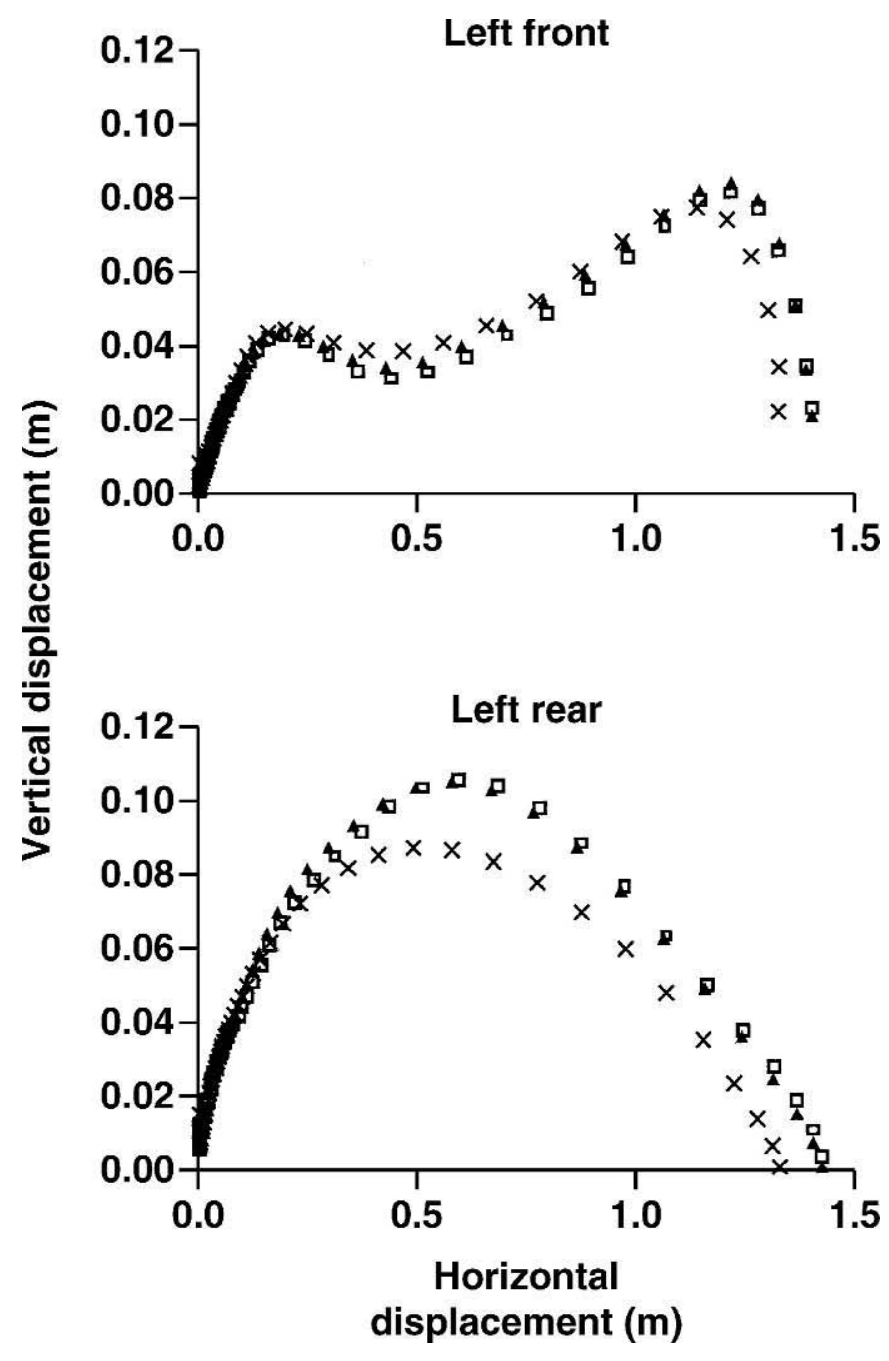

Figure 2. Mean trajectories of the left front and left rear hoof during the swing phase based on an average stride per cow calculated for healthy cows $(\square)$, or cows with sole lesions $(\mathbf{\Lambda})$, or sole ulcers $(\times)$.

speed were all different from those in healthy cows. Sole ulcers are considered painful (Whay et al., 1998), and it is likely that cows with these injuries reduce loading on the affected limb. In the present study, cows having SU both shortened their strides and walked more slowly than healthy cows. By slowing the speed of each hoof, the loading of the affected limb should be more gradual and reduce the peak forces, or impact, at the time the hoof hits the ground (Buchner et al., 1996). One study (Scott, 1989) in cattle and another in horses (Hood et al., 2001) measured forces in walking lame and nonlame animals and found that the loading was often reduced on affected limbs.

The stride cycle, with alternating sequence of diagonal and ipsilateral limb use, and the pattern of double and triple support observed in this study, was originally described by Gambaryan (1974). Our study is the first to quantify kinematically this stride cycle for cattle, and provides a unique contribution to the field of dairy cattle lameness by comparing the cycle for cows with and without SU. Cows having SU increased the proportion of triple support during the stride ( $42 \mathrm{vs.} 18 \%$ ) and had longer stance times ( $0.91 \mathrm{vs.} 0.69 \mathrm{~s})$ compared with healthy cows. These results also support the idea that cows having injuries such as SU may try to reduce the loading on an injured limb by distributing the load between 3 legs for as much time as possible. More detailed studies of limb loading in cattle, including force plate data, are needed to more fully understand how cows respond to hoof injuries.

Stride height of cows having SU was less than for healthy individuals, but the reason for this difference is unclear. Differences in stride height have also been observed in horse studies. For example, Stashak (2002) reported that the stride height of lame horses was lower than that of nonlame horses, but an explanation for this difference was not provided.

No significant differences were found between stride variables of healthy cows and those having SL. It could be that less severe injuries, such as minor SL, are not painful enough to alter gait. Indeed, Whay et al. (1997) investigated the relationship between SL, nociception, and a qualitative measure of gait in dairy cattle, and reported that only cows having more severe SL had abnormal gait. Alternatively, changes in gait may only occur when injuries are located in the weight-bearing zone of the hoof. Corr et al. (1998) found that broiler birds housed on mesh flooring often had foot lesions on the metatarsal pad. The authors suggested that this normally nonweight-bearing part of the foot had a lower threshold to pressure damage than other areas of the foot. Van der Tol et al. (2002) reported that the greatest plantar pressures in the dairy cow hoof were on the sole. In our study, $71 \%$ of cows in the SL group had lesions on the sole. Future research in this area may help to identify which sites of injury are important in dairy cow gait, but this will require reasonable sample sizes for different injuries in different locations.

Location, number, and severity of injuries varied among cows in this study. For example, in the SL group, lesions were located on the left front hoof for some cows and on the right rear hoof for others. Almost two-thirds of cows with hoof pathologies had more than 1 injury and nearly half of the SL cows had moderate to severe hemorrhages. Averaging across affected and unaffected hooves may have masked differences among group gait profiles. Hoof trajectories of 1 cow (cow 13) were used to illustrate that multiple injuries may affect gait in a number of ways. The right rear hoof trajectory of this cow was shortened and lowered, probably due to the 


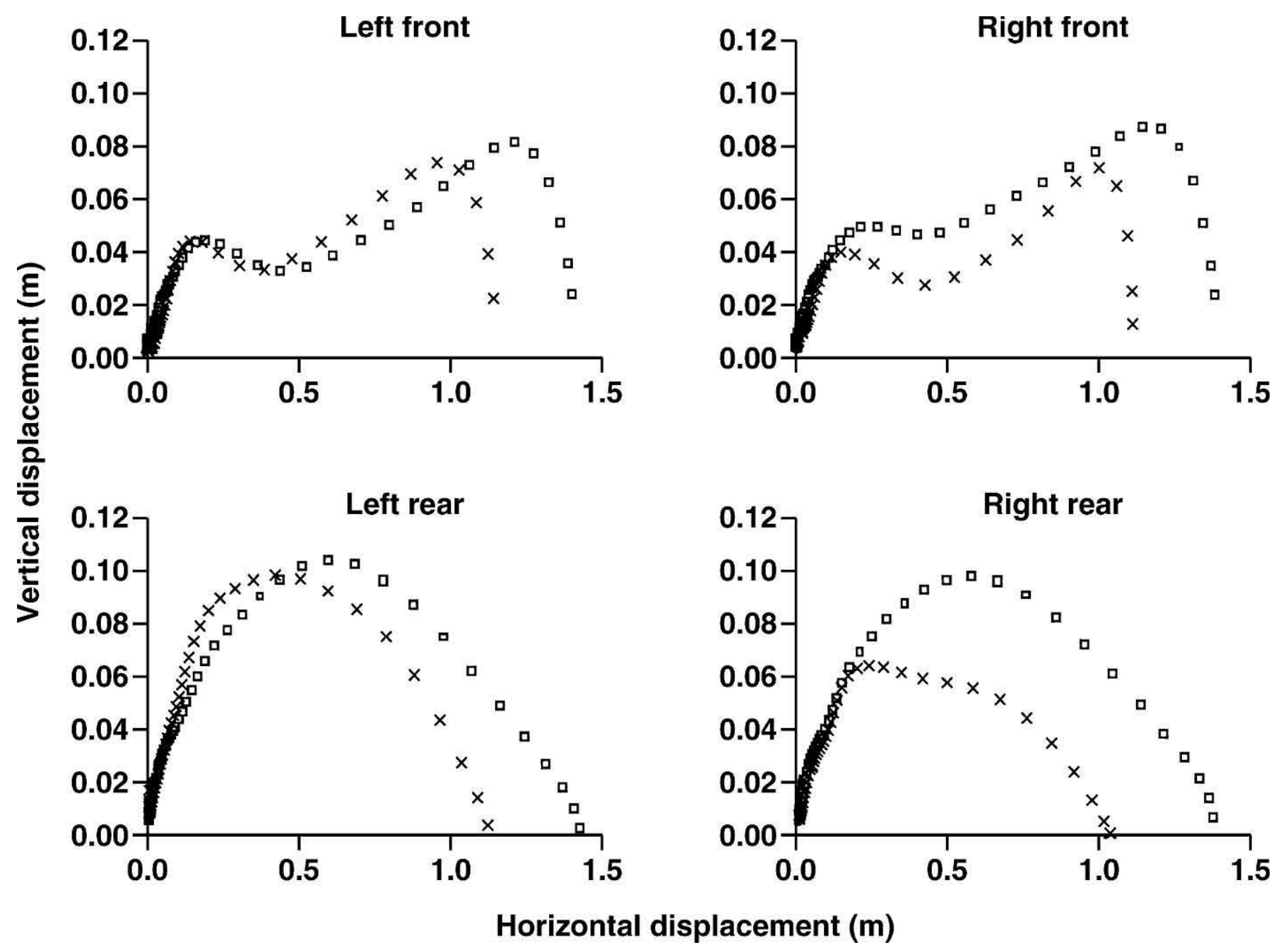

Figure 3. Mean hoof trajectories for cow $13(x)$ and healthy cows $(\square ; n=17)$ during the swing phase, shown separately for each of 4 hooves.

presence of a sole ulcer on this hoof. It is more difficult to explain, however, the altered left front hoof trajectory, as only a minor SL was observed on this hoof. Future research needs to investigate how cows alter their gait in response to a single painful injury before attempting to predict responses to injuries in multiple locations.

The variable time course of injury development may have increased variation in the current study. In our study, the presence of injuries at the time of video recording was determined through hoof examinations 8 to 9 wk after the end of the trial, but this may not have captured all injuries. Another potential source of variation in the current study is that cows were allowed to walk at their natural pace. Walking speed is in itself an interesting measure, but it likely affects other stride variables. Future work using treadmills could control walking speed.
It is evident from the results of this study that kinematic gait analysis is an objective and accurate research tool able to identify cows having SU. At this stage, kinematic gait analysis is likely impractical for use on commercial farms, but technological advances, such as marker-free systems (Green et al., 2000), would facilitate such applications in the future.

In conclusion, analyses of cow gait using kinematic techniques showed distinct differences among cows with no visible hoof pathologies and those with painful injuries such as SU. Our study clearly demonstrated that cows with SU altered their gait in an apparent attempt to reduce loading the affected leg for as long as possible during the stride cycle. More detailed analysis is needed to determine if other pathologies also have characteristic effects on gait that could be useful in early detection of lameness. 


\section{ACKNOWLEDGMENTS}

We thank the faculty, staff, and students at University of British Columbia's Dairy Education and Research Centre and the University's Animal Welfare Program, especially Nelson Dinn, José Fregonesi, David Fraser, Anne Marie de Passillé, Jeff Rushen, Tim Shelford, and the late Jim Shelford for their help during the study. We also thank Erin Bell for conducting hoof health examinations. This research was funded by the Natural Sciences and Engineering Research Council of Canada through the Industrial Research Chair in Animal Welfare, and by contributions from the BC SPCA, the BC Veterinary Medical Association, the Dairy Farmers of Canada, the Beef Cattle Industry Development Fund, the BC Dairy Foundation, and others listed at www.agsci.ubc.ca/animalwelfare.

\section{REFERENCES}

Barrey, E. 1999. Methods, applications and limitations of gait analysis in horses. Vet. J. 157:7-22.

Bell, E. 2004. Description of claw horn lesions and associated risk factors in dairy cattle in the lower Fraser Valley, British Columbia. M.S. Thesis, The University of British Columbia, Vancouver, BC, Canada.

Bergsten, C., and A. H. Herlin. 1996. Sole haemorrhages and heel horn erosion in dairy cows: The influence of housing system on their prevalence and severity. Acta Vet. Scand. 37:395-408.

Buchner, H. H. F., H. H. C. M. Savelberg, H. C. Schamhardt, and A. Barneveld. 1996. Limb movement adaptations in horses with experimentally induced fore- or hindlimb lameness. Equine Vet. J. 281:63-70.

Ceballos, A., D. Sanderson, J. Rushen, and D. M. Weary. 2004. Improving stall design: Use of 3-D kinematics to measure space use by dairy cows when lying down. J. Dairy Sci. 87:2042-2050.

Clarkson, M. J., D. Y. Downham, W. B. Faull, J. W. Hughes, F. J. Manson, J. B. Merritt, R. D. Murray, W. B. Russell, J. E. Sutherst, and W. R. Ward. 1996. Incidence and prevalence of lameness in dairy cattle. Vet. Rec. 138:563-567.

Corr, S. A., C. C. McCorquodale, and M. J. Gentle. 1998. Gait analysis of poultry. Res. Vet. Sci. 65:233-238.

Gambaryan, P. P. 1974. Page 28 in How mammals run: Anatomical adaptations. Halsted Press, New York, NY.

Green, R. D., L. Guan, and J. A. Burne. 2000. Video analysis of gait for diagnosing movement disorders. J. Elect. Imaging 9:16-21.

Green, L. E., V. J. Hedges, Y. H. Schukken, R. W. Blowey, and A. J. Packington. 2002. The impact of clinical lameness on the milk yield of dairy cows. J. Dairy Sci. 85:2250-2256.

Greenough, P. R., and J. J. Vermunt. 1991. Evaluation of subclinical laminitis in a dairy herd and observations on associated nutritional and management factors. Vet. Rec. 128:11-17.
Herlin, A. H., and S. Drevemo. 1997. Investigating locomotion of dairy cows by use of high speed cinematography. Equine Vet. J. Suppl. 23:106-109.

Hood, D. M., I. P. Wagner, D. D. Taylor, G. W. Brumbaugh, and M. K. Chaffin. 2001. Voluntary limb-load distribution in horses with acute and chronic laminitis. Am. J. Vet. Res. 62:1393-1398.

Keegan, K. G., D. A. Wilson, D. J. Wilson, B. Smith, E. M. Gaughan, R. S. Pleasant, J. D. Lillich, J. Kramer, R. D. Howard, C. BaconMiller, E. G. Davis, K. A. May, H. S. Cheramie, W. L. Valentino, and P. D. Van Harreveld. 1998. Evaluation of mild lameness in horses trotting on a treadmill by clinicians and interns or residents and correlation of their assessments with kinematic gait analysis. Am. J. Vet. Res. 59:1370-1377.

Manske, T., J. Hultgren, and C. Bergsten. 2002. Prevalence and interrelationships of hoof lesions and lameness in Swedish dairy cows. Prev. Vet. Med. 54:247-263.

Manson, F. J., and J. D. Leaver. 1988. The influence of concentrate amount on locomotion and clinical lameness in dairy cattle. Anim. Prod. 47:185-190.

National Research Council. 2001. Nutrient Requirements for Dairy Cattle. National Academy of Science, Washington, DC.

O'Callaghan, K. 2002. Lameness and associated pain in cattle-Challenging traditional perceptions. In Pract. 24:214-219.

O'Callaghan, K. A. O., P. J. Cripps, D. Y. Downham, and R. D. Murray. 2003. Subjective and objective assessment of pain and discomfort due to lameness in dairy cattle. Anim. Welf. 12:605-610.

Phillips, C. J. C., and I. D. Morris. 2000. The locomotion of dairy cows on concrete floors that are dry, wet, or covered with a slurry of excreta. J. Dairy Sci. 83:1767-1772.

Russell, A. M., G. J. Rowland, S. R. Shaw, and A. D. Weaver. 1982. Survey of lameness in British dairy cattle. Vet. Rec. 111:155-160.

Scott, G. B. 1989. Changes in limb loading with lameness for a number of Friesian cattle. Br. Vet. J. 145:28-38.

Somers, J. G. C. J., K. Frankena, E. N. Noordhuizen-Stassen, and J. H. M. Metz. 2003. Prevalence of claw disorders in Dutch dairy cows exposed to several floor systems. J. Dairy Sci. 86:2082-2093.

Sprecher, D. J., D. E. Hostetler, and J. B. Kaneene. 1997. A lameness scoring system that uses posture and gait to predict dairy cattle reproductive performance. Theriogenology 47:1179-1187.

Stashak, T. S. 2002. Examination for lameness. Pages 113-183 in Adam's Lameness in Horses, 5th ed. T. S. Stashak, ed. Lippincott, Williams \& Wilkins, Fort Collins, CO.

Van der Tol, P. P. J., J. H. M. Metz, E. N. Noordhuizen-Stassen, W. Back, C. R. Braam, and W. A. Weijs. 2002. The pressure distribution under the bovine claw during square standing on a flat substrate. J. Dairy Sci. 85:1476-1481.

Warnick, L. D., D. Janssen, C. L. Guard, and Y. T. Gröhn. 2001. The effect of lameness on milk production in dairy cows. J. Dairy Sci. 84:1988-1997.

Whay, H. R., A. E. Waterman, and A. J. F. Webster. 1997. Associations between locomotion, claw lesions and nociceptive threshold in dairy heifers during the peripartum period. Vet. J. 154:155-161.

Whay, H. R., A. E. Waterman, A. J. F. Webster, and J. K. O'Brien. 1998. The influence of lesion type on the duration of hyperalgesia associated with hindlimb lameness in dairy cattle. Vet. J. 156:23-29.

Winter, D. A. 1991. Page 18 in The Biomechanics and Motor Control of Human Gait: Normal, Elderly and Pathological. 2nd ed. University of Waterloo Press, Waterloo, ON, Canada. 